\title{
Mode field diameter preserving fiber tapers
}

Noordegraaf, Danny; Maack, M. D.; Skovgaard, P. M. W.; Sørensen, M. H.; Broeng, Jes; Lægsgaard, Jesper

\section{Published in:}

Optics Letters

Link to article, DOI:

10.1364/OL.36.004524

Publication date:

2011

Document Version

Publisher's PDF, also known as Version of record

Link back to DTU Orbit

Citation (APA):

Noordegraaf, D., Maack, M. D., Skovgaard, P. M. W., Sørensen, M. H., Broeng, J., \& Læggsgaard, J. (2011). Mode field diameter preserving fiber tapers. Optics Letters, 36(23), 4524-4526.

https://doi.org/10.1364/OL.36.004524

\section{General rights}

Copyright and moral rights for the publications made accessible in the public portal are retained by the authors and/or other copyright owners and it is a condition of accessing publications that users recognise and abide by the legal requirements associated with these rights.

- Users may download and print one copy of any publication from the public portal for the purpose of private study or research.

- You may not further distribute the material or use it for any profit-making activity or commercial gain

- You may freely distribute the URL identifying the publication in the public portal

If you believe that this document breaches copyright please contact us providing details, and we will remove access to the work immediately and investigate your claim. 


\title{
Mode field diameter preserving fiber tapers
}

\author{
D. Noordegraaf ${ }^{1,2, *}$ M. D. Maack, ${ }^{1}$ P. M. W. Skovgaard, ${ }^{1}$ M. H. Sørensen, ${ }^{1}$ J. Broeng, ${ }^{1}$ and J. Lægsgaard ${ }^{2}$ \\ ${ }^{1}$ NKT Photonics A/S, Blokken 84, DK-3460 Birkerød, Denmark \\ ${ }^{2}$ DTU Fotonik, Technical University of Denmark, DK-2800, Denmark \\ ${ }^{*}$ Corresponding author: dno@nktphotonics.com
}

Received September 22, 2011; accepted September 30, 2011;

posted October 18, 2011 (Doc. ID 155022); published November 22, 2011

\begin{abstract}
An approach for preserving the mode field diameter (MFD) in fiber tapers is demonstrated. The approach utilizes concentric dual-core fibers, which couple light from an inner core to an outer core through a taper. Fibers with a $6 \mu \mathrm{m}$ MFD feedthrough and a $15 \mu \mathrm{m}$ polarization maintaining feedthrough are demonstrated experimentally. Simulations of the MFD in the tapered dual-core fibers are also presented. (c) 2011 Optical Society of America

OCIS codes: $\quad 060.5295,060.4005,060.2340$.
\end{abstract}

Fused fiber-based combiners for coupling pump and signal light into active fibers are essential components for making fiber lasers and amplifiers [1-5]. These combiners typically have a tapered section that increases the intensity of the pump by reducing the pump guide area. In order to include a signal feedthrough in these combiners, one needs to control the mode field diameter (MFD) of the signal light through the tapered section. Such a control can be achieved using dual-core fibers. These can be realized with a pedestal design that consists of a step-index core, with a highly doped region in the center [6,7]. In the untapered fiber, light is guided in a central step-index core; in the tapered fiber, it is guided in a second step-index pedestal core. In the tapered region, light is coupled adiabatically between the two cores.

In this Letter, we describe an alternative approach based on a concentric dual-core structure with a stepindex core and a microstructured cladding region. In the untapered section of the fiber, light is guided in a Gedoped core. When the fiber is tapered, the light couples adiabatically to the core defined by a triangular photonic crystal fiber (PCF) structure of air holes. The advantage of this approach is that a large taper ratio can be achieved with only two cores, where the light is guided in a single-mode waveguide throughout the tapered section. This minimizes the risk of light scattering to higherorder modes (HOMs). Furthermore, since the MFD in a large mode area PCF is proportional to the air hole pitch of the fiber [8], the dual-core PCF approach offers a larger degree of tailoring of the MFD in the down-tapered region. A dual-core PCF was first demonstrated by Eggleton et al. [9]. In this Letter, a low NA Ge-doped center of a PCF enabled the writing of Bragg and long period gratings in the fiber.

The structure of the fabricated dual-core fiber is shown in Fig. 1. In the center of the fiber, the step-index core can be seen and around this core the triangular structure of air holes. Except for the doped center, the material of the fiber is pure silica. The step-index core is Ge-doped and has a diameter of $5.4 \mu \mathrm{m}$ and an NA of 0.14 . This results in a fiber with an MFD of $6.1 \mu \mathrm{m}$ and a HOM cut-off wavelength of $990 \mathrm{~nm}$. The air hole pitch is $18 \mu \mathrm{m}$, and the light in the core mode of the untapered fiber is unaffected by the presence of the holes. This is due to a small overlap between the core mode and the air hole structure, and because the effective index of a large pitch microstructured cladding approaches the index of silica. The diameter of the holes relative to the pitch is 0.48 . The taper fiber is designed to maintain a $6 \mu \mathrm{m}$ MFD for a taper ratio of 3.1. Figure 2 shows a calculation of the MFD in the fiber as a function of air hole pitch (solid blue curve). The calculation is made using a full vectorial mode solver based on the plane-wave expansion method [10]. When the fiber is tapered, the MFD initially decreases slightly and then increases. This follows the normal behavior of a step-index core. As the guiding of the step-index core becomes weaker, the air holes approach the center of the fiber and gradually take over the guiding of the light. This decreases the MFD once again. For reference, Fig. 2 shows the MFD as a function of pitch in a pure step-index fiber without the presence of air holes (dashed curve), and in a pure PCF without the presence of the step-index core (dashed-dotted curve).

To ensure a low taper loss, the adiabatic criterion has to be fulfilled [11- 13$]$

$$
\frac{d r}{d z} \leq \frac{r}{2 \pi}\left(\beta_{1}-\beta_{2}\right)=\frac{r}{L_{B}},
$$

where $r$ is the radius of the fiber core, $z$ is the length direction of the taper, and $\beta_{1}$ and $\beta_{2}$ are the propagation constants of the core and cladding mode, respectively. The beat length $L_{B}$ between the core and cladding mode is defined as $L_{B}=2 \pi /\left(\beta_{1}-\beta_{2}\right)$. From Eq. (1), it can be seen that the taper slope $(d r / d z)$ scales inversely proportional to the beat length. The purple full curve in Fig. 2 shows the beat length between the core mode and the first HOM. The beat length has a maximum value of $L_{B \text { max }}=0.39 \mathrm{~mm}$. For a simple linear taper, the taper slope will be the same over the entire taper. The maximum beat length and the total taper ratio (TR) will

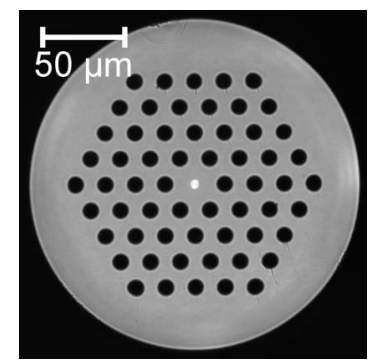

Fig. 1. Microscope cross-sectional image of air hole-based $6 \mu \mathrm{m}$ MFD feedthrough taper fiber. 


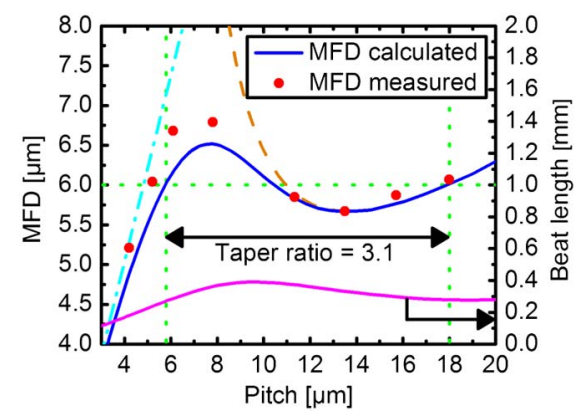

Fig. 2. (Color online) MFD as a function of air hole pitch for the $6 \mu \mathrm{m}$ MFD feedthrough taper fiber. The full curve shows the simulated MFD and the dots show the measured MFD at different positions along the taper. The vertical dotted lines indicate the pitch of the taper fiber in the tapered and untapered end, where a $6 \mu \mathrm{m}$ MFD is maintained. The dashed curve indicates the MFD for a pure step-index fiber and the dashed-dotted curve indicates the MFD for a pure PCF. The purple curve shows the beat length between the core mode and the first cladding mode.

therefore define the length of the taper $(L)$ in order to be adiabatic:

$$
L \geq(\mathrm{TR}-1) L_{B, \max }
$$

With a taper ratio of 3.1 the minimum taper length to ensure an adiabatic linear taper is $L=0.82 \mathrm{~mm}$.

The fiber is tapered using a filament-based GPX glass processing station from Vytran [14]. This is done by careful control of the filament power in order to prevent a collapse of the air holes. A long taper length of $3 \mathrm{~mm}$ is chosen in order to be sure that the taper is adiabatic and has low loss. In Fig. 2, the experimentally measured MFD of the fiber is shown at different positions along a taper (red dots). The measurements were made using a $1064 \mathrm{~nm}$ light source and an IR camera, and are in good agreement with the simulations. In Fig. 3 , two of the measured near fields of the taper fiber are shown. In Fig. 3(a), the near-field of the untapered fiber is shown, where the fiber pitch is $18 \mu \mathrm{m}$. A circular mode is observed and the MFD is measured to $6.1 \mu \mathrm{m}$. In Fig. 3(b), the near-field of the fiber tapered to a pitch of $5.2 \mu \mathrm{m}$ is shown. A hexagonal mode, characteristic for the PCF, is observed and the MFD is measured to $6.0 \mu \mathrm{m}$. Hence, an MFD close to $6 \mu \mathrm{m}$ is maintained when tapering the fiber by a factor of 3.1 .

An important parameter when making combiners is the loss in the taper. In order to evaluate this loss, a Corning HI1060 fiber is spliced to both the tapered and the untapered end of the taper fiber. The HI1060 fiber has an MFD of $6.2 \mu \mathrm{m}$ at a wavelength of $1060 \mathrm{~nm}$, matching the MFD in both ends of the taper fiber. The combined loss in the two splices and the taper is measured to be $0.55 \mathrm{~dB}$ at a wavelength of $1064 \mathrm{~nm}$. The loss in the two splices is estimated to $\sim 0.1 \mathrm{~dB}$ for the HI1060 fiber to the untapered fiber, and $\sim 0.2 \mathrm{~dB}$ for the HI1060 fiber to the tapered fiber. The reason for the higher splice loss to the tapered fiber is due to the need to preserve the air holes with a cold splice and due to the slight reduction in the overlap between the modes caused by the hexagonal mode shape of the PCF. The taper loss is therefore

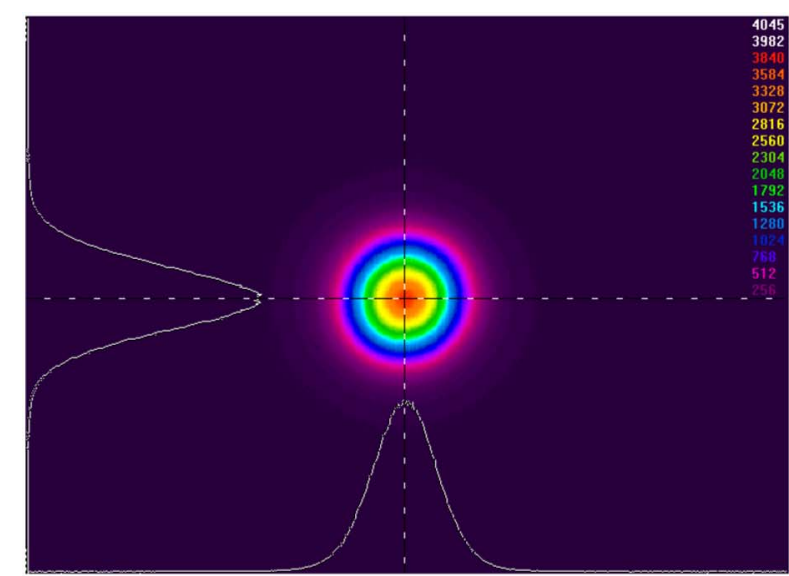

(a)

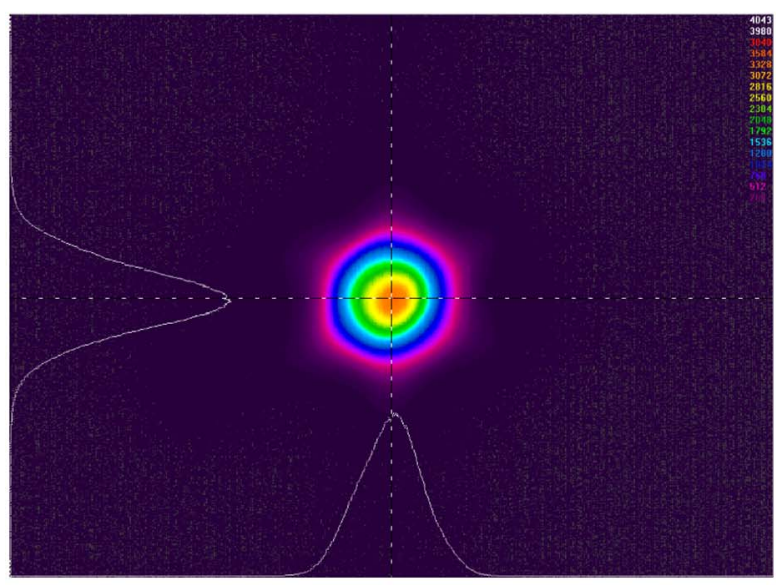

(b)

Fig. 3. (Color online) Experimentally obtained near-field images of $6 \mu \mathrm{m}$ MFD feedthrough taper fiber. (a) Untapered fiber, (b) fiber tapered by a factor of 3.5.

$\sim 0.25 \mathrm{~dB}$ and indicates that an adiabatic transition between the two cores in the tapering is achieved.

For high-power double-clad fiber lasers and amplifiers, a polarization maintaining (PM) signal feedthrough and a larger MFD than $6 \mu \mathrm{m}$ are generally required. A $15 \mu \mathrm{m}$ MFD taper fiber is therefore investigated, with a similar design as the $6 \mu \mathrm{m}$ taper fiber. On either side of the core, an air hole is replaced with a Boron-doped stress rod in order to ensure PM operation. Figure 4(a) shows a microscope image of the taper fiber. The step-index core diameter is $13.3 \mu \mathrm{m}$ and the HOM cut-off wavelength is $\sim 980 \mathrm{~nm}$. The air hole structure has a pitch of $47 \mu \mathrm{m}$ and an air hole diameter divided by pitch of 0.45 .

Simulations are made to examine the evolution of the MFD through the taper. For the simulations, a perfect structure without stress elements is used. The results are shown in Fig. 4(b). The solid blue curve indicates the MFD of the fiber, the dashed curve shows the MFD of a pure step-index core fiber, and the dasheddotted curve shows the MFD of a pure PCF. The full purple curve in Fig. 4(b) shows the beat length between the core mode and the first HOM. The beat length has a maximum value of $L_{B, \max }=2.69 \mathrm{~mm}$. For a taper ratio of 3.4, an MFD close to $15 \mu \mathrm{m}$ will be maintained through the taper. From Eq. (2), the minimum taper length to ensure an adiabatic linear taper is $L=6.46 \mathrm{~mm}$. To ensure that 


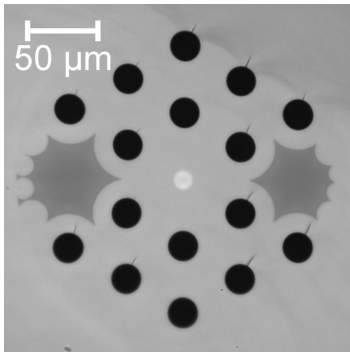

(a)

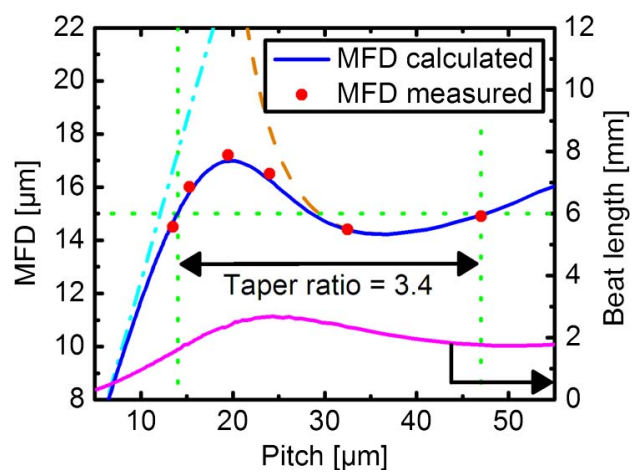

(b)

Fig. 4. (Color online) (a) Microscope cross-sectional image of air hole-based $15 \mu \mathrm{m}$ MFD feedthrough PM taper fiber. (b) MFD as a function of air hole pitch for the $15 \mu \mathrm{m}$ MFD feedthrough fiber. The full curve shows the simulated MFD and the dots show the measured MFD at different positions along the taper. The vertical dotted lines indicate the pitch of the taper fiber in the tapered and untapered end, where a $15 \mu \mathrm{m}$ MFD is maintained. The dashed curve indicates the MFD for a pure stepindex fiber and the dashed-dotted curve indicates the MFD for a pure PCF. The purple curve shows the beat length between the core mode and the first cladding mode.

the taper is adiabatic, a longer taper length of $15 \mathrm{~mm}$ is chosen. In the untapered fiber, the MFD at a wavelength of $1064 \mathrm{~nm}$ is $14.9 \mu \mathrm{m}$. When the fiber is tapered down to a pitch of $13.5 \mu \mathrm{m}$, the air hole structure facilitates guiding, resulting in a hexagonal mode with an MFD of $14.5 \mu \mathrm{m}$. Figure 4(b) shows the measured MFD of the fiber at different positions along the taper (red dots). The measured MFD is in good agreement with the simulations.

In order to measure the loss in the taper, a $15 \mu \mathrm{m}$ MFD single-mode PM fiber is spliced to the untapered end of the taper fiber and to the down-tapered end. The combined loss in the two splices and the taper is measured to be $0.70 \mathrm{~dB}$ at a wavelength of $1064 \mathrm{~nm}$. Assuming the same splice loss as for the $6 \mu \mathrm{m}$ fiber investigation, the loss in the taper is $\sim 0.30 \mathrm{~dB}$. This is comparable to what was achieved for the $6 \mu \mathrm{m}$ taper fiber, again indicating a smooth adiabatic transition in the taper.

For making PM combiners, it is important that light does not couple between the two polarization states of the taper fiber. The polarization cross talk is therefore measured with a polarized light source. It is found that through the combined setup of two splices and the taper, the cross talk between the two polarization states is below $-18 \mathrm{~dB}$. This fulfills the requirements for typical PM combiners.

In conclusion, we have demonstrated a method for preserving the MFD in fiber tapers. The concept is experimentally demonstrated with both a $6 \mu \mathrm{m}$ MFD feedthrough and a $15 \mu \mathrm{m}$ MFD PM feedthrough. A low loss in the two tapers is demonstrated and also a low polarization cross talk in the $15 \mu \mathrm{m}$ feedthrough fiber. The experimental results of the measured MFD in the tapers are in good agreement with the simulations.

\section{References}

1. F. Gonthier, L. Martineau, N. Azami, M. Faucher, F. Séguin, D. Stryckman, and A. Villeneuve, Proc. SPIE 5335, 266 (2004).

2. F. Séguin, A. Wetter, L. Martineau, M. Faucher, C. Delisle, and S. Caplette, Proc. SPIE 6102, 61021N (2006).

3. M. Nakai, K. Shima, M. Saito, and T. Kitabayashi, Proc. SPIE 6453, 645319 (2007).

4. M. D. Nielsen, M. H. Sørensen, A. Liem, M. Kozak, and P. M. W. Skovgaard, Proc. SPIE 6453, 64532C (2007).

5. D. Noordegraaf, M. D. Nielsen, P. M. W. Skovgaard, S. Agger, K. P. Hansen, J. Broeng, C. Jakobsen, H. R. Simonsen, and J. Lægsgaard, in Proceedings of IEEE Conference on Lasers and Electro-Optics (IEEE, 2009), pp. 1-2.

6. K. B. Sparks, "Optical fiber with low taper induced loss," U.S. patent 7,046,890 (May 16, 2006).

7. W. R. Holland and T. F. Taunay, "Fiber based laser combiners," U.S. patent application 12/760,547 (April 14, 2010).

8. M. D. Nielsen, N. A. Mortensen, J. R. Folkenberg, and A. Bjarklev, Opt. Lett. 28, 2309 (2003).

9. B. J. Eggleton, P. S. Westbrook, R. S. Windeler, S. Spälter, and T. A. Strasser, Opt. Lett. 24, 1460 (1999).

10. S. G. Johnson and J. D. Joannopoulos, Opt. Express 8, 173 (2001).

11. W. J. Stewart and J. D. Love, in Proceedings of European Conference on Optical Communication (IEEE, 1985), pp. 559-562.

12. J. D. Love and W. M. Henry, Electron. Lett. 22, 912 (1986).

13. T. A. Birks and Y. W. Li, J. Lightwave Technol. 10, 432 (1992).

14. Vytran, http://www.vytran.com. 